\title{
Forecasting of Population Narcotization under the Implementation of a Drug Use Reduction Policy
}

\author{
Sergey Mityagin, ${ }^{1}$ Carlos Gershenson $\left(\mathbb{D},{ }^{1,2}\right.$ and Alexander Boukhanovsky ${ }^{1}$ \\ ${ }^{1}$ ITMO University, Saint Petersburg, Russia \\ ${ }^{2}$ Universidad Nacional Autónoma de México, Mexico, Mexico \\ Correspondence should be addressed to Carlos Gershenson; cgg@unam.mx
}

Received 8 October 2019; Accepted 19 February 2020; Published 17 March 2020

Academic Editor: José Manuel Galán

Copyright (C) 2020 Sergey Mityagin et al. This is an open access article distributed under the Creative Commons Attribution License, which permits unrestricted use, distribution, and reproduction in any medium, provided the original work is properly cited.

\begin{abstract}
In this paper, we present an approach to drug addiction simulation and forecasting in the medium and long terms in cities having a high population density and a high rate of social communication. Drug addiction forecasting is one of the basic components of the antidrug policy, giving informational and analytic support both at the regional and at the governmental level. However, views on the drug consumption problem vary in different regions, and as a consequence, several approaches to antidrug policy implementation exist. Thereby, notwithstanding the fact that the phenomenology of the population narcotization process is similar in the different regions, approaches to the modeling of drug addiction may also substantially differ for different kinds of antidrug policies. This paper presents a survey of the available antidrug policies and the corresponding approaches to the simulation of population narcotization. This article considers the approach to the construction of the regression model of anesthesia on the main components formed on the basis of indicators of social and economic development. The substantiation of the chosen method is given, which is associated with a significant correlation of indicators, which characterizes the presence of a small number of superfactors. This allows us to form a conclusion about the general level of development of the region as the main factor determining the drug addiction. A new model is proposed for one of the most widespread antidrug policies, namely, the drug use reduction policy. The model helps determine the significant factors of population narcotization and allows to estimate its damage. The model is tested successfully using St. Petersburg data.
\end{abstract}

\section{Introduction}

Drug addiction is a problem that affects various spheres of social life, both at the regional and at the national level, as it deeply influences the socioeconomic development of a given territory and the cultural, emotional, and psychological state of the society.

Despite the obvious fact that the spreading of drug addiction as well as drug trafficking affects both the standard of living and the society's survival conditions, at present, there is no common approach to the problem. On the one hand, drug addiction is often considered some sort of a disease and the drug users are considered persons to be treated and rehabilitated [1]. On the other hand, drug trafficking and consumption are an illegal activity, which then should be examined from the criminological point of view [2]. From this latter point of view, drug consumers and distributors violate the applicable law [3, 4]. Additionally, a third point of view of the problem exists-one that considers the problem as a social phenomenon and as some sort of social deviation, caused by the internal problems and contradictions in the society [5]. This point of view was developed relatively recently and is based on the observation that different types of drugs spread in different social layers of the population. The process depends, among other things, on the psychological readiness of the society for drug acceptance or, in contrast, drug rejection.

Thus, as it was established earlier in [2], public opinion plays an important role in the spreading of drugs. The situation connected with drug consumption and illegal 
trafficking is just a variation of the entire social situation, developing as a result of interactions between drug consumers and drug distributors, preceded by the formation of an accepting attitude towards drug consumption in the society.

Government and public antidrug policies, implemented in a given territory, play an essential role in the regulation of such interactions. As a rule, the applicable particular kind of the public antidrug policy depends on the cultural and historical foundations of the society, which stipulate the formation of one or another approach to the problem of drug addiction.

Accordingly, different approaches to the public antidrug policy are practiced in the world, but three of them can be acknowledged as being fundamental - the policy of drug use reduction, the policy of microharm reduction, and the policy of total harm reduction. The choice of the particular approach depends on regional features and the inhabitants' attitude to the drug situation as indicated above. The particular antidrug policy, implemented in a given territory, determines the approach to informational and analytic support of the policy, and this support in turn includes processes of analysis, forecasting, and planning [6].

At the same time, it should be noted that, regardless of the particular policy, the basic phenomenology of the drug consumption process, including all accompanying phenomena such as the drug addiction syndrome and the abstinence syndrome, is similar for different territories [7].

Thus, approaches to the simulation and forecasting of processes of population narcotization, on the one hand, should take into account features of the particular antidrug policy implemented in the given territory and, on the other hand, should be based on the common phenomenological aspects of drug addiction. For this reason, this paper presents and discusses an approach to the simulation of population narcotization processes that is based on the usage of both microlevel and macrolevel models. The macrolevel model takes into account the features of the given antidrug policy implemented in the territory and the features of the key indicator accounting system. The microlevel model, by contrast, takes into account common phenomenological features of drug spreading in the society.

\section{Different Types of Drug Policies}

The final aim of obtaining forecasting estimates of the drug situation is to form reasonable and sound plans of a territory development, which imply the reduction of damage from drug addiction in the society. The spirit of the state management system in the antidrug domain plays an important role in this because it is an essential factor determining not only the dynamics but also the entire structure of social processes, characterizing the drug situation.

The policy of drug use reduction focuses on eliminating or, at least, on decreasing drug use in the society. This kind of policy is traditionally used in the USA, and it is formulated in the National Drug Control Strategy [8]. It also occupies an important place in the antidrug policies of European countries such as Switzerland and France, and additionally in Middle East countries and the Russian Federation. The policy of drug use reduction is based on the notion that drug-related problems emerging in a society, family, or social group can be solved only if the drug use would be stopped or minimized. For people, who do not use drugs, this paradigm assumes prevention programs, worked out to prevent drug consumption.

The policy of microharm reduction focuses on decreasing medium harm to individual drug users and people not using drugs. This policy is based on the notion that drug consumption is only moderately harmful inherently, and steps can be taken to reduce the risks associated with the drug use.

The term "harm reduction" can be interpreted rather widely, to the extent that this flexibility can lead to misunderstanding, which in turn makes it possible for controversial policies with the same pronounced aim of "harm reduction" to be introduced. For example, a policy can be expressed by the program of syringe exchange for drug users in order to reduce the spreading of infectious diseases and thus to reduce harm to drug users. And a second policy can be expressed by the law about obligatory imprisonment for drug users in order to reduce harm to people not using drugs. The two approaches cannot be more different.

Therefore, it is essential to determine the research aims accurately during the analysis because there are plenty of negative effects associated with drug usage, each having its consumption and antidrug conditions. Switzerland, the Netherlands, and Canada are among the countries using a microharm reduction policy. The microharm reduction approach has its roots in public health insurance and in the movement for drug consumption normalization.

The policy of total harm reduction combines essential features of the drug use reduction policy and the microharm reduction policy [9]. Antidrug policy activities can influence the popularity, intensity, and harm from drug usage. The "total harm reduction" term covers all these phenomena together. Macroharm is defined as the product of popularity, intensity, and average harm from drugs. Total harm is defined as the sum of the macroharms. This approach is closely connected with risk analyses, economic damage analyses, and so on. At the moment, this approach exists primarily as a theoretical model.

So, from the practical point of view, antidrug activities can range from the harder ones (use reduction) to the less hard ones (harm reduction): police supervision of street drug trade, police raids, precursor trade restriction, arrest for minor violations, drug testing, and intervention to the private life of drug users, such as treating and rehabilitating them.

\section{Overview of Drug Forecasting Models}

As a rule, regardless of the chosen antidrug policy, data about the drug-related diseases and mental or behavioral disorders and data from opinion polls are often used for forecasting the narcotization of a given population.

The European Monitoring Centre for Drugs and Drug Addiction (EMCDDA), a decentralized organization working 
in the European Union, publicizes annual reports about the drug issue situation in the member states of the European Union, and it also collects and provides up-to-date empirical data. A study [10], conducted and published by the EMCDDA, provides a survey of modeling methods for the socalled "high-risk drug use" and "problem drug use" categories in Europe. A forecasting method for drug addiction spreading, using a geographic information system and developed under the Drug Incidence \& Prevalence Estimation Program (DIPEP), is presented in $[10,11]$.

Drug addiction spreading is simulated similarly to that of infections in epidemiology. In this paradigm, the key concepts are modes of infection transmission, risk groups, the prevalence of infection, its geographical distribution, and epidemic cycle. Drug addiction prevalence zones are simulated by the method of inverse distance weighting (IDW). The study [11] observes frequency and prevalence simulation for drug usage in the United Kingdom.

An essential feature of the models used under the policy of drug use reduction is the necessary consideration of implicit drug users. The study [11] suggests using a set of dynamic models, which exploit available statistic data, for the purpose of a quantitative estimation of such drug users. However, the key thesis of the paper [11] states that it would be necessary to further reduce the uncertainty caused by the implicit ("dark" or hidden) nature of the drug-related processes. Methods of stratified calibrated samples, probabilistic simulation, methods of multiple capture and recapture, and estimation of the connection between heavy drug prevalence and crime frequencies are used. Multiple methods and models applied to a single target population make the judgment about trends and drug user quantity more accurate.

A model using multiple indicators [12-14] can be offered as an alternative for the drug situation forecasting. The model in question applies a hypothesis about different "cause-effect" associations between drug situation indicators. Three groups of indicators are distinguished: social, legal, and medical. The authors note the universality of this model, its usability in research of different socioeconomic scenarios, and the model's adaptability to income data. The practical use of the model has brought some unexpected and counterintuitive results.

For example, the model proposed in the study [12] describes sequential transition of individuals between states related to drugs. The "healthy" people are considered an initial state. The next state is for the "soft drug users." The "hard drug users" are considered a final state. Despite the fact that this scheme is not confirmed by any empirical data, it allows us to examine drug addiction as a social process with relatively discrete phenomenological states. The composition of states is formed under certain social mechanisms.

Several studies use the class of dynamic models $[13,15]$. The term "dynamic model" covers methods of system analysis and time-series simulation, which are applied for a drug use spreading estimation. Dynamic models, unlike static ones, describe processes in time. These methods are able to support not only descriptive analyses but also the simulation of the genuine processes underlying the drug situation. An example process for the description can be the process of state change in drug users in a "capture-markrecapture" framework. The "capture-recapture" models are separated into two classes: one with an open population and one with a closed population. Models with a closed population assume that the population does not change during the period of research, and models with an open population consider population increases and decreases. Models with a closed population are simpler and are targeted primarily to short-time-period analyses and are generally not applicable to relatively long time periods. In such cases, more complex models using an open population are used.

In J. Caulkins' study [15], the elasticity of demand for cocaine and heroin is estimated on DUF and STRIDE data sets provided by the USA National Institute of Justice and the Drug Enforcement Administration. The author tries to find an answer to the following question: How much would consumption decline in the case of a price increase? Differential equations are chosen as a mathematical analysis method. The analysis exposes a high elasticity of demand as a response to market phenomena. In the conclusion of the study, the author associates the increase in cocaine and heroin use in the 1980s with an essential drug price decline. Consequently, activities causing an increase of drug prices are expected to be useful for antidrug policy implementation, according to this work.

Thereby, the simulation of social processes related to drug use spreading in the society under a drug use reduction policy is usually coming along with a problem of income data collection and a problem of accompanying narcotization features, like latency. In general, these problems enhance the complexity of the applied mathematical models and the laboriousness of income data preparation. For example, in the USA, with its drug use reduction policy, such surveys as ADAM (testing prisoners for signs of drug use), NSDUH and SAMHDA (national surveys), and National Roadside Survey (testing drivers for alcohol and drugs) are taken regularly in order to improve the reliability of the drug usage estimates. Additionally, the STRIDE system is used for elicitation of the information about the results of laboratory analysis of samples of drugs from materials of criminal cases on drug-related crimes.

Based on the above, the issue of informational and analytic support in the antidrug sphere requires a more universal approach, applicable to different antidrug policies and considering political, cultural, and moral aspects of population narcotization processes. Developing a two-level model of drug addiction spreading at both the microlevel and the macrolevel as presented below is one such approach.

\section{The Drug Situation}

This paper presents the development of a population narcotization forecasting model under the antidrug policy implemented in St. Petersburg. The simulation of the narcotization in the city requires that we take into account a set of essential regional characteristics and the given antidrug policy implemented in the territory. 
In the Russian Federation, a drug use reduction policy is implemented; therefore, the drug consumption can be considered, on the one hand, a social process with an epidemic nature and, on the other hand, an illegal behavior of individual members of the society. As it was mentioned above, an important attribute of the drug use reduction policy is recognition of the existence of a significant proportion of implicit drug users.

The "hidden drug users" are defined as the drug users who are not on the official state account and therefore do not receive treatment. Registration of drug users is performed either by a voluntary appearance of the drug user to the profile health system department or as a result of the activities of law enforcement and public safety authorities including the Federal Service for Drug Control [16].

The hidden drug users exist outside the activity of drug control authorities and health authorities and are not included in the state statistics. They can stay in this state for a quite a long time until they are obliged to seek medical care or fall in the sphere of influence of drug control authorities. The hidden drug users can be divided into consumers of "heavy" and "light" drugs depending on the types of drugs they consume. Thus, the hidden drug users are the latent part of the population narcotization process, and their quantity cannot be directly evaluated. Indirect methods of evaluation of the quantity of the hidden drug users require a separate study [17].

The simplest metric of evaluation of the quantity of the hidden drug users called the "latency coefficient" is used presently. The latency coefficient is defined as the ratio of the actual number of drug users to the number of drug users in the state account.

The latency coefficient in St. Petersburg, according to the research [17], is estimated between 8 and 10 units referring to the consumption of "hard" drugs and between 40 and 50 units referring to the consumption of "light" drugs. This means that the assessment of the real number of soft drug consumers may be 50 times greater than the number of registered drug users; as a result, in the article [18], drug trafficking crimes are included in the category of high latent crimes. It should be noted that this situation is typical for the type of antidrug policy implemented in the Russian Federation.

Due to its unique geographical location, St. Petersburg has been historically a major transport hub, making it also a tense region in terms of drug traffic. Figure 1 presents the regions of the Russian Federation and the estimated tension level related to the consumption and trafficking of drugs. Threshold levels are marked in greyscale: PC1-precrisis state of the first type, characterized by an increased share of drug users in the total population of the corresponding age; PC2-precrisis state of the second type, characterized by the possibility of a crisis emergence; $\mathrm{C} 1$-crisis state of the first type, meaning a need to mobilize the efforts of the region to fight population narcotization; and $\mathrm{C} 2$ - crisis state of the second type, meaning a need to attract external resources to the region to counteract narcotization [19].

It is noticeable that almost all regions with high levels of drug addiction are located on roads and rail routes connecting the regions of the North Caucasus to Central Russia and to the port of St. Petersburg and the regions bordering the countries of Central Asia.

So in St. Petersburg, there are trade routes from the western European countries through Moldova, Ukraine, and Belarus; also, we experience a "seasonal" intensification of smuggling opium with the concealment of fruits and vegetables from Afghanistan and Tajikistan through Uzbekistan, Kyrgyzstan, Azerbaijan, and Kazakhstan. The presence of drug transit routes and the proximity of the region to the external borders of the Russian Federation may determine the amount of traffic of drugs and the prevalence of certain types of drugs. The economic situation in the region not only characterizes the purchasing power for buying drugs but also creates a "fashion" for certain types of drugs. Another important factor is the ability to cultivate narcotic plants in the soil or the availability of raw materials for their production.

Altogether three groups of factors are considered for the drug situation in St. Petersburg, including the characteristics of drug use $\left(I_{1}, I_{2}, I_{3}, I_{4}\right)$, the crime rate in their turnover $\left(I_{5}, I_{6}, I_{7}, I_{8}, I_{9}, I_{10}, I_{11}\right)$, and the public attitude towards the drug situation $\left(I_{12}, I_{13}, I_{14}, I_{15}\right)$. The factors of these three groups are determined by the macroeconomic indicators of life in St. Petersburg.

However, before considering these factors of population narcotization more closely, it should be noted that, in different age groups and social groups, a different sensitivity to the drug problems is also observed. Let us consider the age structure of the drug users and the age structure of the population at whole during the development of models of drug addiction on the example of St. Petersburg again. The age structure of the St. Petersburg population is denoted as $P=\left\{p_{i}\right\}$ and the age structure of the drug users is denoted as $N=\left\{n_{i}\right\}$, where $p_{i}$ and $n_{i}$ are the quantity of people living in the territory and the quantity of the drug users of age $i$ years, respectively (see Figure 2 ).

In Figure 2, one can observe the presence of a significant increase in the population of age 16-20-the most critical life period in terms of drug addiction. At the same time, it is seen that the peak number of drug addicts has been gradually shifting towards higher ages recently. However, starting from 2014 again, we experience an emergence of a new "wave" of drug users in the younger age groups, presumably due to the emergence of new types of drugs.

Thus, in the age structure of the population, it is possible to allocate specific ages or age intervals, which are more sensitive in terms of drug use. In other words, the probability of initiation of drug use varies in different age groups, and we will consider the probability of drug use by people of the corresponding age as a basic concept of the proposed approach to the population narcotization simulation.

\section{Multifactor Forecasting Models of Drug Addiction}

Our population narcotization model is based on an assessment of the probability of an individual to change his/her phenomenological state under the process of population 


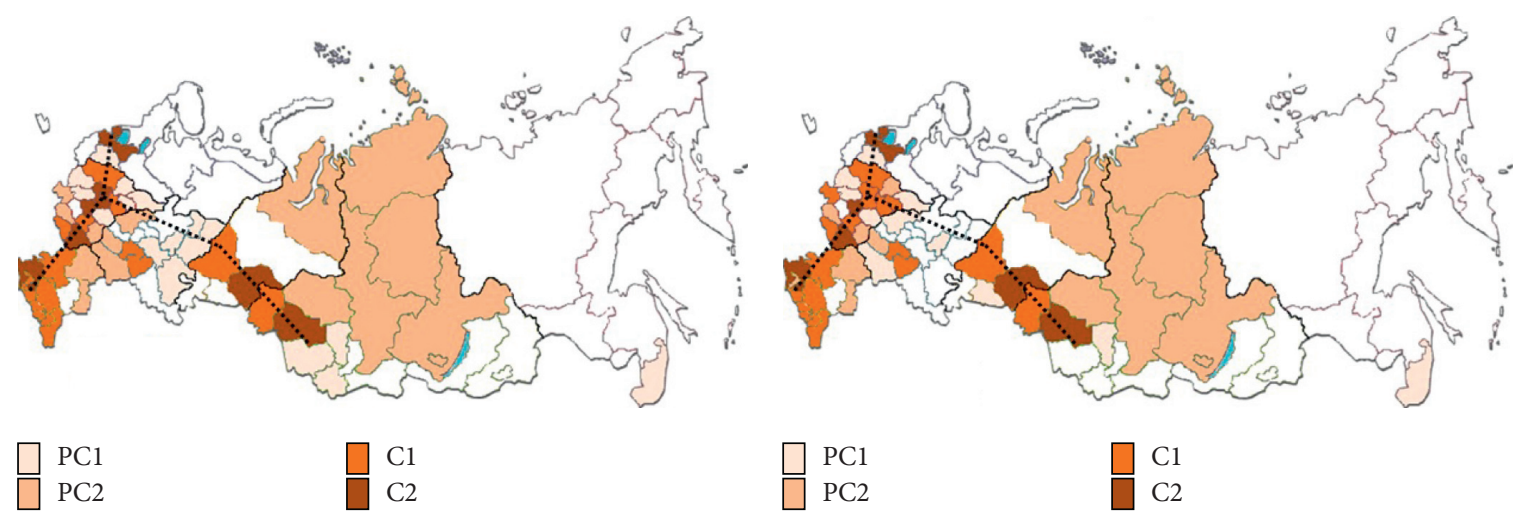

(a)

(b)

Figure 1: Allocation of the Russian Federation regions on the indicators: (a) registered drug user quantity; (b) quantity of registered crimes connected with drug trafficking.

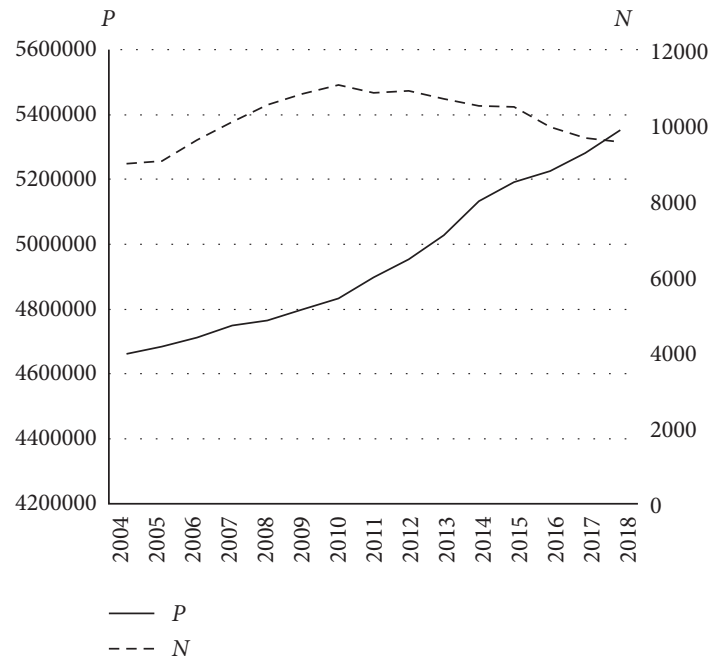

(a)

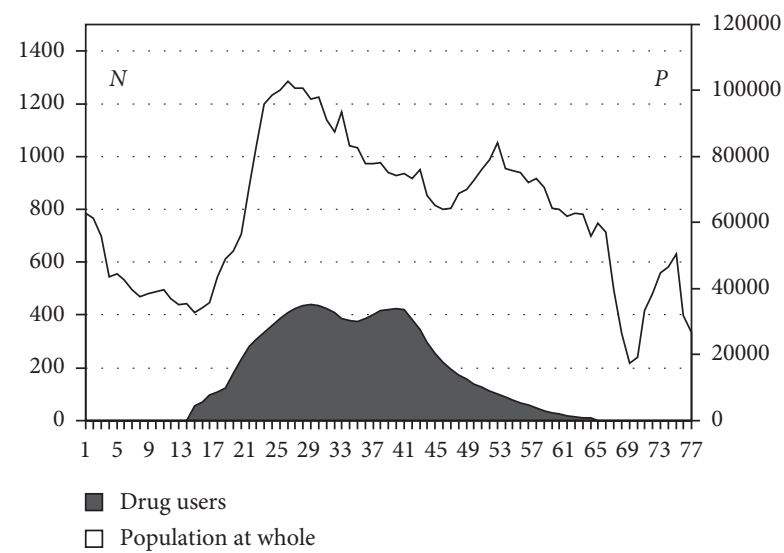

(c)

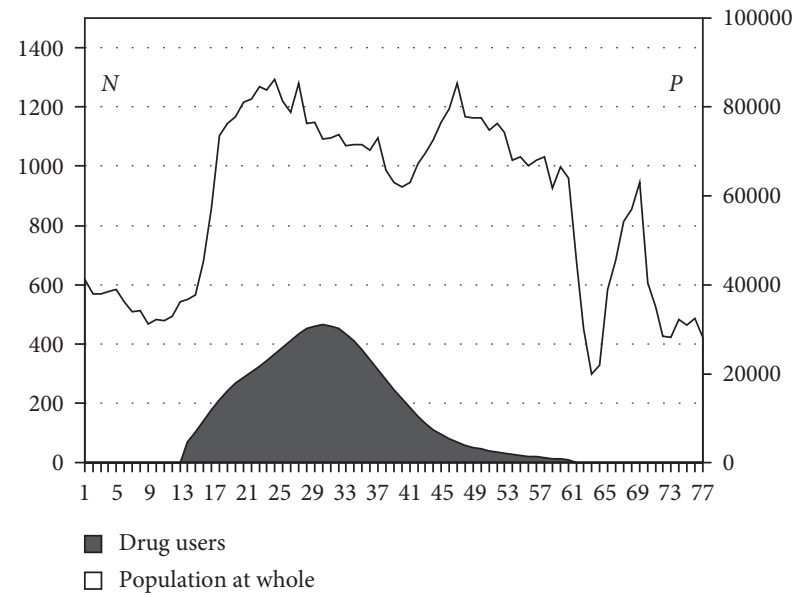

(b)

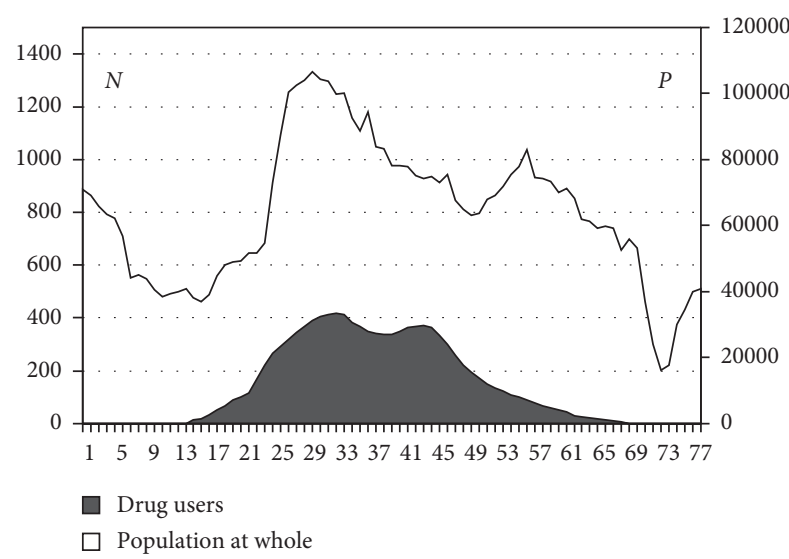

(d)

Figure 2: Age structure of the St. Petersburg population: common dynamics of groups $P$ and $N$ (a) at whole and in years (b) 2009, (c) 2015, and (d) 2018. 
narcotization. Changing the state happens, for example, by the consumption of drugs by a person who has previously not used them, or the transition of a drug user with a syndrome of psychological addiction to a more severe stage.

\subsection{The Microlevel Phenomenological Model of Population} Narcotization. Figure 3 presents a diagram of the phenomenological states of the population narcotization process, used in constructing the microlevel model of population narcotization.

According to the diagram, the phenomenological states of the entire population of the region $P$ can be divided into three main groups: people with immunity to drug addiction, not predisposed to consume any type of drug (I); people with a predisposition to drug addiction $(H)$; and people at risk, having the ability both to consume or not to consume drugs $(R)$. It should be noted that people of the group I may still be subjected to other manifestations of deviant behavior, such as alcoholism. In turn, a predisposition to drug use can be physical or psychological.

In the event of drug use by people of the group $H$ or $R$, they pass into the phenomenological state $D$, which in turn can be divided into two groups: a group $L$ of drug users without drug addiction or having psychological addiction forms only and a group $N$ of drug users having more serious physical addiction forms. The transition of an individual to an appropriate phenomenological state is determined by the probability of his/her transition between states.

The simulation and forecasting of the population narcotization eventually involves obtaining reasonable estimates for the number of drug addicts in the given area. In terms of our model, this means an estimation of the number of individuals in the phenomenological state $N$, which in turn requires simulation and forecasting of the probability of individuals' transition to the state $N$ from other states. Since, in the present study, we rely on the data of the official state statistics, which virtually have no information about the number and composition of the groups $L$, $I, R$, and $H$, we will consider the transition of individuals to the state $N$ directly from the state $P$. An illustration of the structure and dynamics of these groups is shown in Figure 2.

Let the probability of such a transition, which corresponds to the onset of a drug addiction syndrome for an individual, be denoted as $g$ (see Figure 3 ). The transition probability of an individual to the group $N$ is then estimated according to the expression

$$
g_{i}=\frac{n_{i}}{p_{i}}
$$

where $p_{i}$ is the number of people of age $i$ in the area and $n_{i}$ is the number of drug users of age $i$ in the area. Simulation of the dynamics concerning other phenomenological states can be carried out in a similar way.

\section{The Macrolevel Matrix Model of Population Narcotization}

To describe the state transitions quantitatively, a matrix demography model has been used, whose operation is based

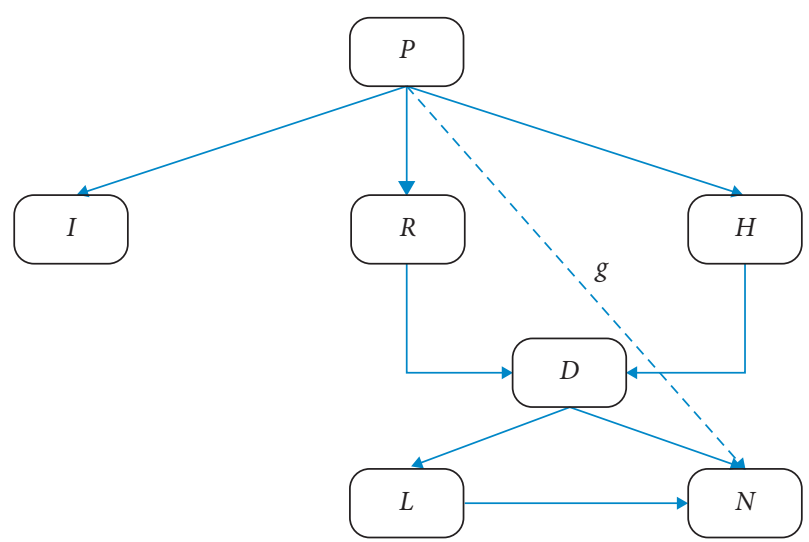

FIGURE 3: Structure of the states of the population narcotization process.

on the forecasting of the age and sex structure of the population on the basis of transition probabilities of individuals to the appropriate group $[11,12]$. Let us represent the age structure of the population $(P)$ and the age structure of drug users $(N)$, respectively, in the form

$$
\begin{aligned}
P & =\left(p_{1}, p_{2}, \ldots, p_{100}\right)^{T}, \\
N & =\left(n_{1}, n_{2}, \ldots, n_{100}\right)^{T} .
\end{aligned}
$$

Then, a general expression describing the evolution of the society structure in the area in terms of the matrix model can be written as

$$
\begin{aligned}
& P^{t+1}=F_{\alpha} \cdot P^{t}+W^{t}, \\
& N^{t+1}=F_{\beta} \cdot P^{t+1},
\end{aligned}
$$

where the matrix $P^{t}$ describes the age-sex structure of the population at time $t$, the matrix $N^{t}$ describes the age-sex structure of drug users at time $t$, and the matrix $W^{t}$ describes the migration network taking into account the age structure.

Given the structure of the matrix $P^{t}$, the operators $F_{\alpha}$ (for aging) and $F_{\beta}$ (for narcotization) can be determined as follows:

$$
\begin{aligned}
F_{\alpha} & =\left(\begin{array}{ccccc}
f_{b, 1} & f_{b, 2} & \cdots & f_{b, n-1} & f_{b, n} \\
f_{1} & 0 & \cdots & 0 & 0 \\
0 & f_{2} & \cdots & 0 & 0 \\
\vdots & \vdots & \ddots & \vdots & \vdots \\
0 & 0 & \cdots & f_{n-1} & 0
\end{array}\right), \\
F_{\beta} & =\left(\begin{array}{ccccc}
g_{1} & 0 & \cdots & 0 & 0 \\
0 & g_{2} & \cdots & 0 & 0 \\
\vdots & \vdots & \ddots & \vdots & \vdots \\
0 & 0 & \cdots & g_{n-1} & 0 \\
0 & 0 & \cdots & 0 & g_{n}
\end{array}\right),
\end{aligned}
$$

where $F_{\alpha}$ is the matrix $n \times n$, in which $n$ is the number of age categories considered, $f_{b, i}$-the first line-determines the probability of bearing children by individuals in the respective age group, $f_{i}$ is the probability for individuals of 
every age group $i<n$ to stay alive up to the next age group, and $g_{i}$ is the probability for individuals of the respective age group to move to the group $N$.

Let us consider the formation of the matrix $F_{\beta}$. Obviously, probabilities $g_{i}$ depend on many factors, which may be different for different age groups.

\section{Factors of Population Narcotization}

The composition of factors can itself be varied, and the creation of the list of important factors is a separate research task. In this paper, based on the studies $[6,17,20]$, we will consider the following groups of factors, as mentioned before: the characteristics of drug use $\left(I_{1}, I_{2}, I_{3}, I_{4}\right)$, the crime rate in their turnover $\left(I_{5}, I_{6}, I_{7}, I_{8}, I_{9}, I_{10}, I_{11}\right)$, the public attitude towards the drug situation $\left(I_{12}, I_{13}, I_{14}, I_{15}\right)$, and factors of socioeconomic development of the region reflecting the quality of life in general $\left(I_{16}, I_{17}, I_{18}, I_{19}, I_{20}\right)$. The values of these factors are determined by the results of monitoring of corresponding life indicators.

In this paper, given values of the indicators are adjusted to dimensionless quantities (normalized) in accordance with the following rule: " 0 " corresponds to the minimum value of the index in the observation period and " 1 " corresponds to the maximum value of the index in the observation period.

7.1. Criminality in the Drug Trafficking Sphere. We will consider the following factors as indicators characterizing details of criminality in the drug trafficking sphere [17]:

(1) The number of registered crimes in the drug trafficking sphere $\left(I_{1}\right)$

(2) The proportion of crimes in the drug trafficking sphere $\left(I_{2}\right)$

(3) The number of crimes solved in the drug trafficking sphere $\left(I_{3}\right)$

(4) The number of seized drugs from illegal turnover $\left(I_{4}\right)$

In Figure 4, one can observe the representative dynamics of criminality in the drug trafficking sphere, which shows a decline recorded in the period from 2002 to 2007. In 2008, recovering of the factors $I_{1}, I_{2}$, and $I_{3}$ to the 2001 levels is observed, which is accompanied by a surge in withdrawals of drugs from illegal turnover in 2008. It is noteworthy that the described trends coincide with the activity period of the federal target antidrug program for the period of 2005-2009 [19].

An established feature of the St. Petersburg region is that crimes related to drug trafficking traditionally make a quarter of the total number of registered crimes. And most of the crimes are serious or very serious. According to the structure of offenses, it is noted that the biggest share of offenses consists of those related to drug use and to the appearance of intoxicated individuals in public. Of particular note is that a significant number of administrative offenses related to drug trafficking are committed by the youth, which points to the need to apply drug use forecasting models to every age group, including young groups.
7.2. Drug Addiction. We will consider the following factors as indicators characterizing the level of illegal drug use and drug addiction in St. Petersburg [17]:

(1) The number of registered patients with a diagnosis of "drug addiction" $\left(I_{5}\right)$

(2) The number of patients under supervision with a diagnosis of "drug addiction," established for the first time $\left(I_{6}\right)$

(3) The number of female patients under supervision with a diagnosis of "drug addiction," established for the first time $\left(I_{7}\right)$

(4) The number of teenage patients under supervision with a diagnosis of "drug addiction," established for the first time $\left(I_{8}\right)$

(5) The number of beds in psychiatric clinics and drug dispensary $\left(I_{9}\right)$

Figure 5 shows the dynamics of drug addiction, including the drug addiction of youth. It should be noted that drug addiction was increasing in the period from 2004 to 2007, which correlates with the dynamics of criminality, which in turn includes effects from the development of general laws of the region and from drug addiction spreading.

As a characteristic of the region, it should be noted following [2] that factors of the socioeconomic development of the area and the quality as well as standards of living are less important for the youth than are public approval, the acceptance of drugs, and the effect of "fashion" for some types of drugs among the youth. This is best confirmed by the structure of drug addicts. It is observed that, among the causes of drug addiction among youths under consideration, there is an increase of the proportion of psychostimulants, which are often used as "party" or "club" drugs and are distributed in relatively open communities, compared to the more traditional opium drug communities.

At the same time, it is noted that recovery from the state of addiction is still at a low level, presumably due to the fact that generally only patients with drug-related conditions in a fairly advanced stage are being accounted and treated. This is confirmed by the age structure of drug users, shown in Figure 2.

Therefore, as noted from Figures 4 and 5, in the organization of antidrug activities, the highest level of attention should be paid to the prevention of primary disease spreading among females aged 16-23 years. Social studies [20] show that girls of this age are already starting to use drugs existing in the community and interacting with other young people who have drug experience.

7.3. Acceptance of Drug Use in the Society. Studying the acceptance of drugs and the individuals consuming them, it is essential to take into account the widespread presence of drug use experience in the targeted age and sex groups. We also have to bear in mind the possibility of having a positive image of the drug users, which can be due to the "fashion" of certain types of new drugs and the associated lifestyle. 


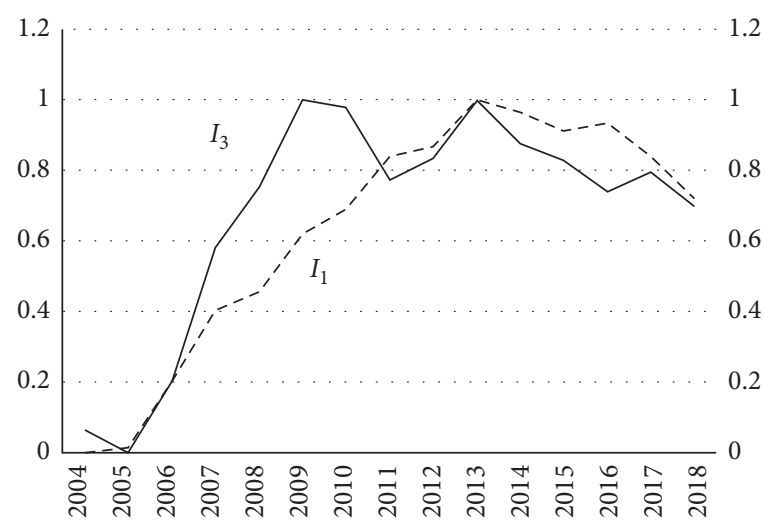

(a)

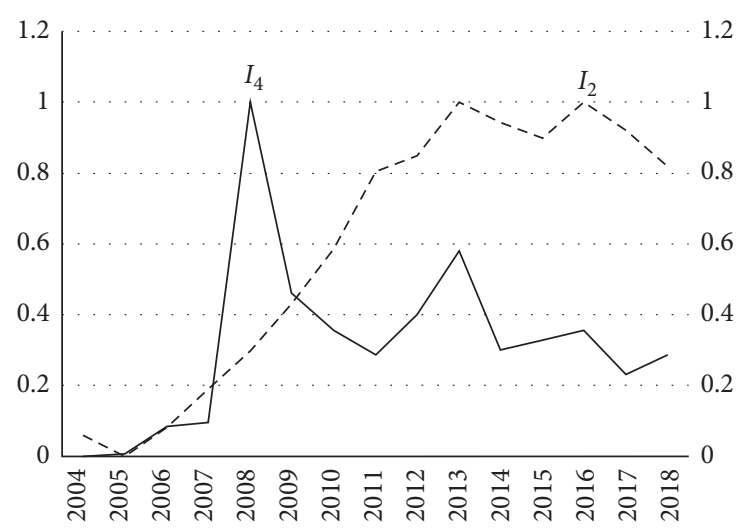

(b)

Figure 4: Dynamics of the factors of the state of criminality in the drug trafficking sphere (normalized values, each to its maximum).

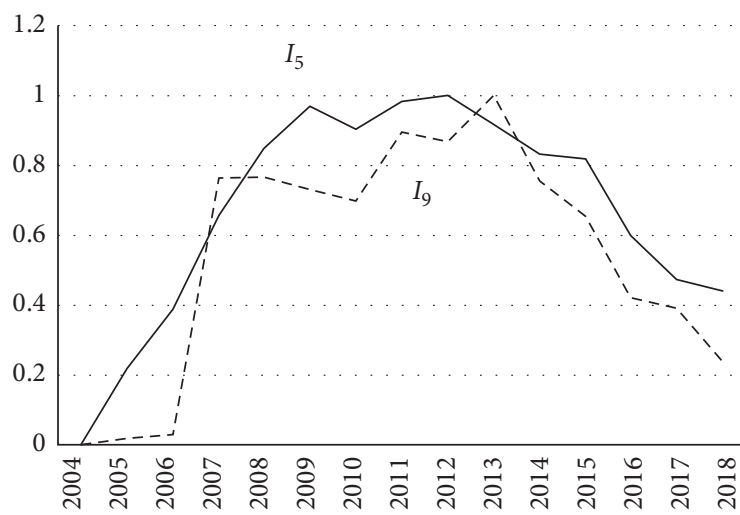

(a)

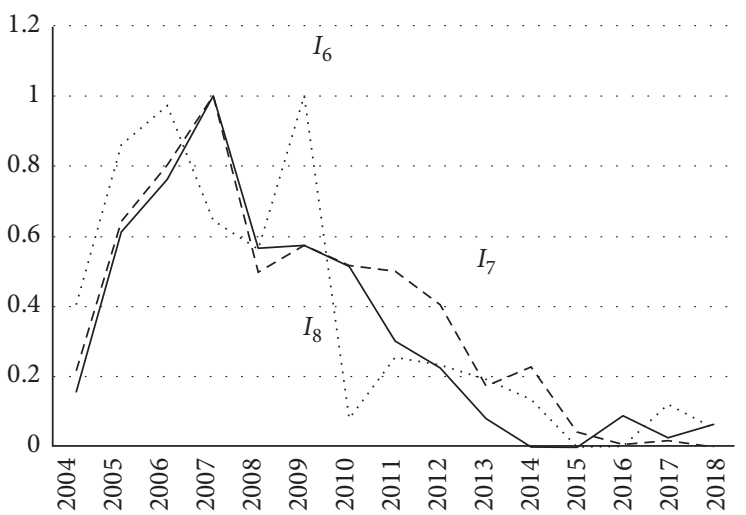

(b)

FIgURE 5: Dynamics of the factors of the level of illegal drug use and drug addiction (normalized values).

We will consider the following factors as indicators characterizing the level of acceptance of drug use [20]:

(1) The proportion of people with an experience with drugs $\left(I_{10}\right)$

(2) The proportion of people exposed to drug users in the region $\left(I_{11}\right)$

(3) The proportion of people with a positive attitude towards tight antidrug policies $\left(I_{12}\right)$

Figure 6 shows the dynamics of factors related to the level of acceptance of drug use, estimated on the basis of sociological surveys regularly conducted in St. Petersburg [17]. The indicator $I_{12}$ is plotted in Figure 6(b) in absolute and normalized values. The absolute values of the indicator are marked on the right axis in the percentage of respondents. It is noted that the 2014 increase in the proportion of individuals recognized in the personal consumption of drugs gives a ground to believe that an increase in the number of juvenile drug addicts, shown in Figure 5, means reducing the latency of the indicators of the number of drug addicts. At the same time, respondents most often admit the use of marijuana, which indicates a high social acceptance of this type of drug, and of heroin, which corresponds to a large proportion of older drug users who began heroin use 5-7 years ago; this is evidenced by the time structure of drug addicts (see Figure 2).

It should be noted that the factor $I_{12}$ turns out not to be significant in absolute terms, which on the one hand is the result of the drug policy implemented in the region and on the other hand is a substantiation of this policy application due to the existing social traditions.

7.4. Related Socioeconomic Factors of Drug Addiction. Since the processes of drug addiction affect almost all spheres of societal life in the population, it is obvious that we cannot study drug use without taking into account the common socioeconomic situation in the area. In particular, the study [17] gives an assessment of the drug addiction process on the basis of sociodemographic indicators. Such indicators are, for example, the following:

(1) Financial incomes of population $\left(I_{13}\right)$

(2) The ratio of average per capita consumer spending related to the cost of minimum food basket $\left(I_{14}\right)$

(3) The number of the unemployed $\left(I_{15}\right)$

(4) The ratio of cash income to a subsistence minimum $\left(I_{16}\right)$ 


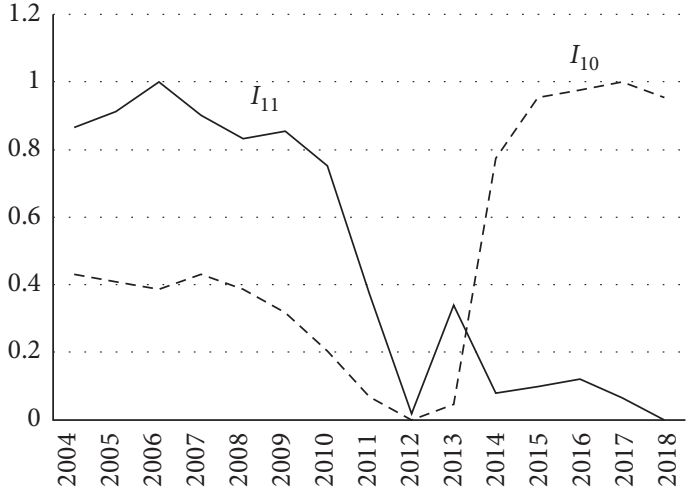

(a)

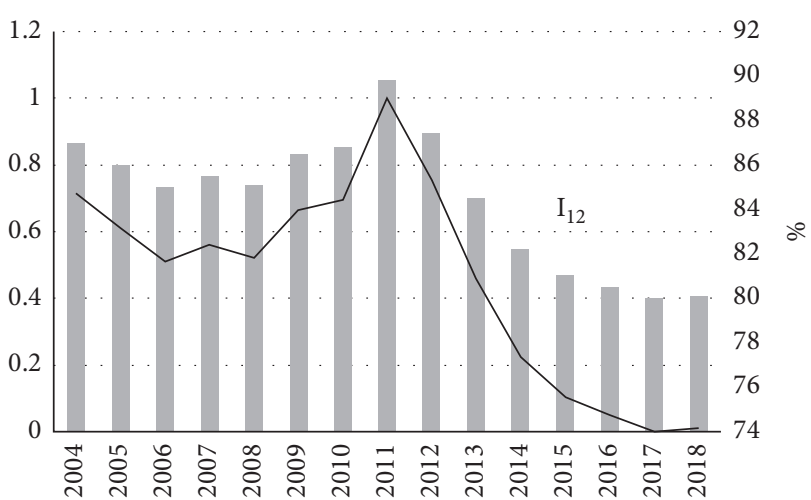

(b)

Figure 6: Dynamics of the factors of the level of loyalty to drug use: (a) indicators $I_{10}$ and $I_{11}$ (normalized values); (b) indicator $I_{12}$ (absolute and normalized values).

(5) The number of registered families in need of better housing conditions $\left(I_{17}\right)$

(6) The concentration of incomes of the population $\left(I_{18}\right)$

(7) The proportion of individuals dissatisfied with life $\left(I_{19}\right)$

(8) The proportion of individuals satisfied with life $\left(I_{20}\right)$

This set of indicators of socioeconomic development cannot be considered exhaustive.

The definition of a set of significant factors of the socioeconomic status of the region in the process of population narcotization is the task of a separate study.

In our work, we will consider indicators $I_{13}, \ldots, I_{20}$ based on the study [19] (Figure 7).

In the St. Petersburg region, the majority of indicators represent the socioeconomic crisis of 2009-2010, expressed in the loss of purchasing power of the population. These effects are also reflected in the indicators of life satisfaction. At the same time, indicators of income concentration and the number of those in need of better housing conditions, chosen as indicators of general living standards, have shown quite positive and stable dynamics. From this, we can conclude that the emotional and psychological state of the society is left influenced by other laws than the welfare and standard of living.

7.5. Considering the Influence of Factors of Population Narcotization in the Model. As noted, the basis of our population narcotization model is the set of probabilities of individuals' transition between phenomenological states. These probabilities are generated separately for each age group and depend on the characteristics of life in the area. Let us study a model of dependence of population narcotization probabilities $g$ from the factors of territorial development $I_{1}, \ldots, I_{20}$. It is almost impossible to highlight the most significant factors in the problem of population narcotization analysis, at least under the implementation of the drug use reduction policy. And, at the same time, a significant correlation between different factors is noted (shown in Table 1), suggesting that there are region-wide patterns of development and that the possibility of reducing the dimension of the problem is present.
Therefore, in this paper, we investigate the variability of the factor space $I_{1}, \ldots, I_{20}$ on the narcotization dynamics $g$. In order to reduce the dimension of the problem, and to identify groups of factors that have the greatest influence, the method of principal component analysis (PCA) is used.

Table 2 shows the evaluation of the importance of 15 principal components calculated for the system of indicators $I_{1}, \ldots, I_{20}$. According to Table 2, we will use the first four principal components, explaining $90 \%$ of the variance. Figure 8 shows the values of the principal components $P_{1}, \ldots, P_{4}$.

Assuming that we have determined $P_{1}, \ldots, P_{4}$, let us define the dependence of the drug addiction probability $g_{i}$ from the estimates of the principal components $P_{1}, \ldots, P_{4}$ by applying a regression model:

$$
g_{i}=\theta_{1} P_{1 i}+\theta_{2} P_{2 i}+\theta_{3} P_{3 i}+\theta_{4} P_{4 i}+\theta_{5}+\varepsilon_{i},
$$

where $g_{i}$ is the probability of transition to a population group of drug users as before, $\theta_{1}, \ldots, \theta_{5}$ are the regression parameters, and $\varepsilon=\left(\varepsilon_{1}, \ldots, \varepsilon_{n}\right)^{T}$ are the normally distributed error terms with a zero mean and variance $D \varepsilon=\sigma^{2} E$, where $E$ is the identity matrix. Probabilities $g_{i}$ of the regression model (5) are estimated directly from the official statistics according to expression (1).

\section{Application of the Model of Population Narcotization to the St. Petersburg Example}

Figure 9 presents the point estimates $g_{i}(1)$ of the transition probabilities to a drug user group $\mathrm{N}$ for the individuals of appropriate ages and their regression approximations. The following graphs show empirical and calculated results for the most important age groups.

Figure 9 shows the dynamics of probability of drug use initiation for persons of 18 years (Figure 9(a)) and 25 years (Figure 9(b)) and the average probability of drug use initiation for all ages (Figure 9(c)). The vertical axis is the value of the probability assessment of drug use initiation.

It is noteworthy that, in 2006, there was a peak of the probability of drug use initiation for persons of 18 years, and 


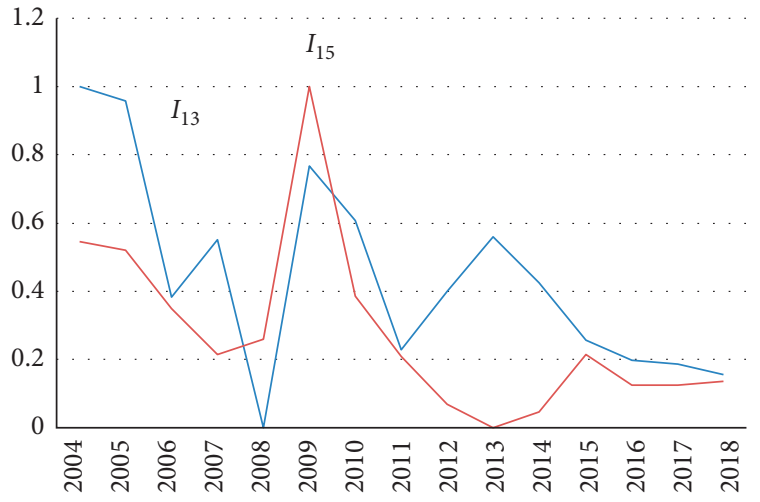

(a)

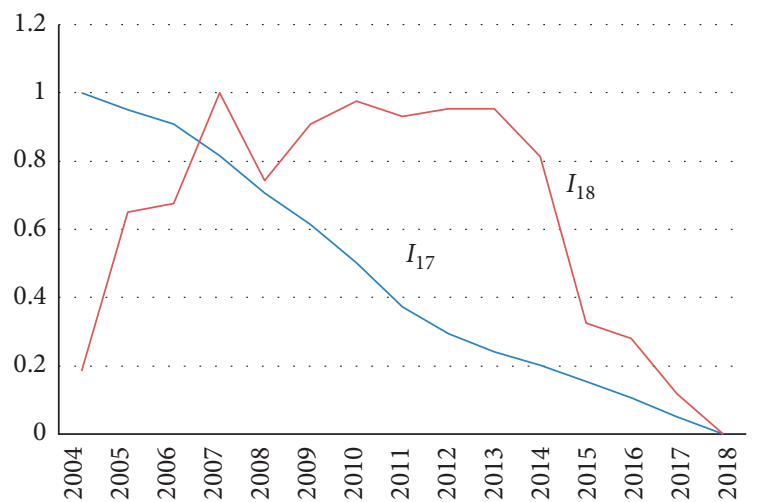

(c)

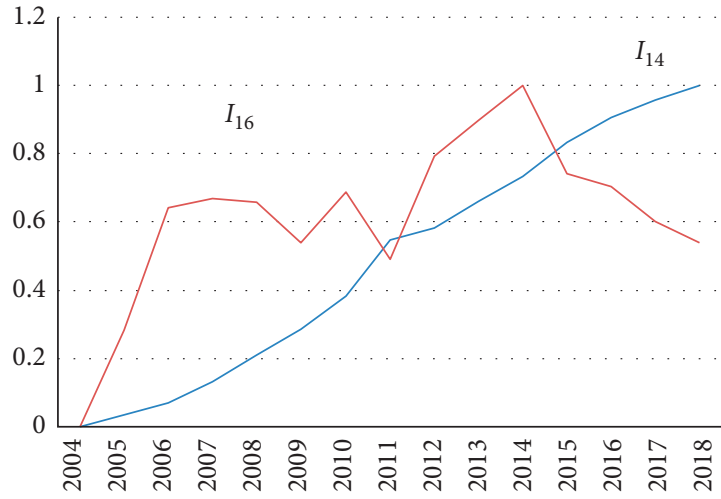

(b)

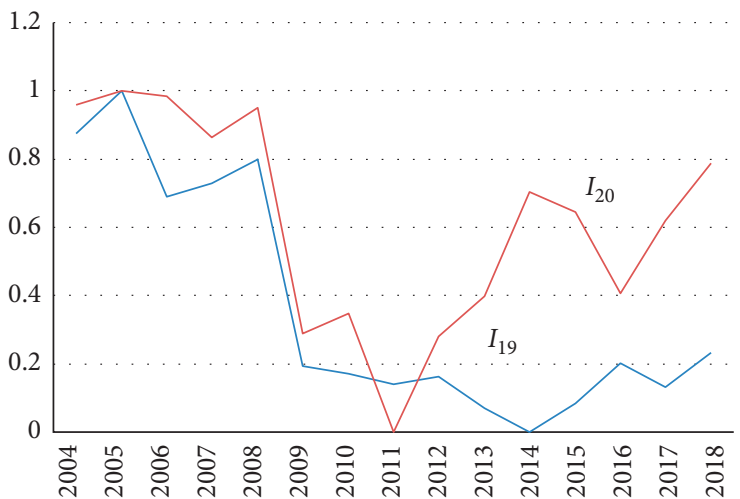

(d)

Figure 7: Dynamics of socioeconomic factors (normalized values).

TABLE 1: Correlation matrix of factors $I_{1}, \ldots, I_{20}$.

\begin{tabular}{|c|c|c|c|c|c|c|c|c|c|c|c|c|c|c|c|c|c|c|c|c|}
\hline & $I_{1}$ & $I_{2}$ & $I_{3}$ & $I_{4}$ & $I_{5}$ & $I_{6}$ & $I_{7}$ & $I_{8}$ & $I_{9}$ & $I_{10}$ & $I_{11}$ & $I_{12}$ & $I_{13}$ & $I_{14}$ & $I_{15}$ & $I_{16}$ & $I_{17}$ & $I_{18}$ & $I_{19}$ & $I_{20}$ \\
\hline$I_{1}$ & & 1 & 1 & 0.4 & 0.8 & 0.2 & 0.2 & 0.2 & 0.8 & 0.2 & 0.2 & 0.2 & 0.2 & 0.8 & 0.2 & 0.6 & 0.2 & 0.4 & 0.2 & 0.2 \\
\hline$I_{2}$ & 1 & & 1 & 0.4 & 0.8 & 0.2 & 0.2 & 0.2 & 0.8 & 0.2 & 0.2 & 0.2 & 0.2 & 1 & 0.2 & 0.6 & 0.2 & .4 & 0.2 & 0.2 \\
\hline$I_{3}$ & 1 & 1 & & 0.6 & 0.8 & 0.2 & 0.2 & 0.2 & 0.8 & 0.2 & 0.2 & 0.2 & 0.2 & 0.8 & 0.2 & 0.6 & 0.2 & 0.2 & 0.2 & 0.2 \\
\hline$I_{4}$ & 0.4 & $0 . .4$ & 0.6 & & 0.8 & 0.2 & 0.2 & 0.2 & 0.8 & 0.2 & 0.2 & 0.2 & 0.2 & 0.8 & 0.2 & 0.8 & 0.2 & & 2 & 0.2 \\
\hline$I_{5}$ & 0.8 & 0.8 & 0.8 & 0.8 & & 0.2 & 0.2 & 0.2 & 1 & 0.2 & 0.2 & 0.2 & 0.2 & 1 & 0.2 & 1 & 0.2 & .8 & .2 & 0.2 \\
\hline$I_{6}$ & 0.2 & 0.2 & 0.2 & 0.2 & 0.2 & & 1 & 0.8 & 0.2 & 0.2 & 0.6 & 0.4 & 0.2 & 0.2 & 0.4 & 0.2 & 0.4 & .2 & .4 & 0.4 \\
\hline$I_{7}$ & 0.2 & 0.2 & 0.2 & 0.2 & 0.2 & 1 & & 0.6 & 0.2 & 0.2 & 0.4 & 0.2 & 0.2 & 0.2 & 0.2 & 0.2 & & 0.4 & .2 & 0.4 \\
\hline$I_{8}$ & .2 & 0.2 & 0.2 & 0.2 & 0.2 & 0.8 & 0.6 & & 0.2 & 0.2 & 0.6 & 0.4 & 0.2 & 0.2 & 0.4 & 0.2 & 0.8 & 2 & 0.4 & 0.6 \\
\hline$I_{9}$ & 0.8 & 0.8 & 0.8 & 0.8 & 1 & 0.2 & 0.2 & 0.2 & & 0.2 & 0.2 & 0.2 & 0.2 & 1 & 0.2 & 1 & 0.2 & 0.8 & 0.2 & 0.2 \\
\hline$I_{10}$ & 0.2 & 0.2 & 0.2 & 0.2 & 0.2 & 0.2 & 0.2 & 0.2 & 0.2 & & 0.2 & 0.2 & 0.2 & 0.2 & 0.2 & 0.2 & 0.2 & 0.2 & 0.2 & 0.6 \\
\hline$I_{11}$ & 0.2 & 0.2 & 0.2 & 0.2 & 0.2 & 0.6 & 0.4 & 0.6 & 0.2 & 0.2 & & 0.6 & 0.6 & 0.2 & 0.8 & 0.2 & 0.8 & 0.2 & 1 & 0.6 \\
\hline$I_{12}$ & 0.2 & 0.2 & 0.2 & 0.2 & 0.2 & 0.4 & 0.2 & 0.4 & 0.2 & 0.2 & 0.6 & & 0.4 & 0.2 & 0.6 & 0.2 & 0.8 & 0.2 & 0.6 & 0.2 \\
\hline$I_{13}$ & 0.2 & 0.2 & 0.2 & 0.2 & 0.2 & 0.2 & 0.2 & 0.2 & 0.2 & 0.2 & 0.6 & 0.4 & & 0.2 & 0.6 & 0.2 & & & & 0.2 \\
\hline$I_{14}$ & 0.8 & 1 & 0.8 & 0.8 & 1 & 0.2 & 0.2 & 0.2 & 1 & 0.2 & 0.2 & 0.2 & 0.2 & & 0.2 & 1 & 0.2 & 0.8 & 2 & 0.2 \\
\hline$I_{15}$ & 0.2 & 0.2 & 0.2 & 0.2 & 0.2 & 0.4 & 0.2 & 0.4 & 0.2 & 0.2 & 0.8 & 0.6 & 0.6 & 0.2 & & 0.2 & 0.6 & 0.2 & 0.6 & 0.2 \\
\hline$I_{16}$ & 0.6 & 0.6 & 0.6 & 0.8 & 1 & 0.2 & 0.2 & 0.2 & 1 & 0.2 & 0.2 & 0.2 & 0.2 & 1 & 0.2 & & 0.2 & 1 & 0.2 & 0.2 \\
\hline$I_{17}$ & 0.2 & 0.2 & 0.2 & 0.2 & 0.2 & 0.4 & 0.2 & 0.8 & 0.2 & 0.2 & 0.8 & 0.8 & 0.6 & 0.2 & 0.6 & 0.2 & & 0.2 & 1 & 0.6 \\
\hline$I_{18}$ & 0.4 & 0.4 & 0.2 & 0.6 & 0.8 & 0.2 & 0.4 & 0.2 & 0.8 & 0.2 & 0.2 & 0.2 & 0.2 & 0.8 & 0.2 & 1 & 0.2 & & 0.2 & 0.2 \\
\hline$I_{19}$ & 0.2 & 0.2 & 0.2 & 0.2 & 0.2 & 0.4 & 0.2 & 0.4 & 0.2 & 0.2 & 1 & 0.6 & 0.6 & 0.2 & 0.6 & 0.2 & 1 & 0.2 & & 0.8 \\
\hline$I_{20}$ & 0.2 & 0.2 & 0.2 & 0.2 & 0.2 & 0.4 & 0.4 & 0.6 & 0.2 & 0.6 & 0.6 & 0.2 & 0.2 & 0.2 & 0.2 & 0.2 & 0.6 & 0.2 & 0.8 & \\
\hline
\end{tabular}

TABLe 2: Evaluation of the importance of the first 15 principal components (PC1-PC15).

\begin{tabular}{|c|c|c|c|c|c|c|c|c|c|c|c|c|c|c|c|}
\hline & $\mathrm{PC} 1$ & PC2 & PC3 & PC4 & PC5 & PC6 & PC7 & PC8 & PC9 & $\mathrm{PC} 10$ & $\mathrm{PC} 11$ & $\mathrm{PC} 12$ & $\mathrm{PC} 13$ & $\mathrm{PC} 14$ & PC15 \\
\hline & 006 & 617 & & - & 266 & 2 & & & 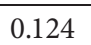 & & & & & 030 & T \\
\hline & & & & & & & & & & & & & & 0 & 0 \\
\hline Cumulative proportion & 0.592 & 0.726 & 0.813 & 0.890 & 0.925 & 0.960 & 0.972 & 0.982 & 0.990 & 0.994 & 0.996 & 0.998 & 1 & 1 & 1 \\
\hline
\end{tabular}




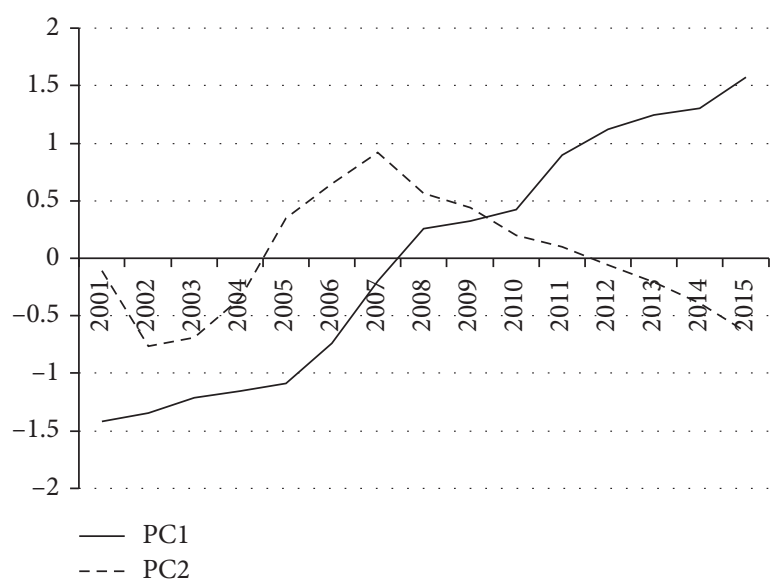

(a)

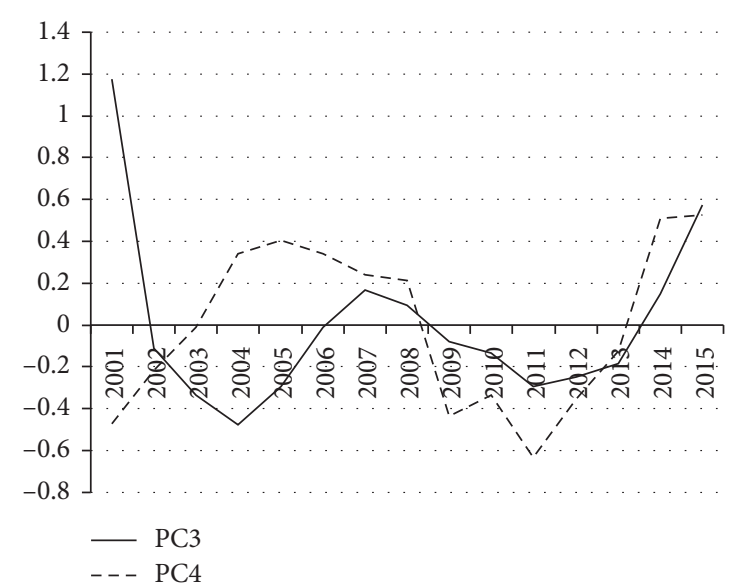

(b)

FIgURe 8: Values of the first four principal components $P_{1}, \ldots, P_{4}$ for the system of indicators $I_{1}, \ldots, I_{20}$.

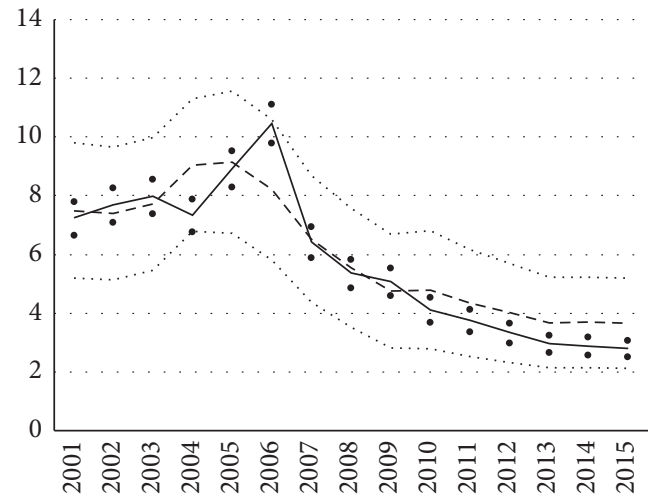

(a)

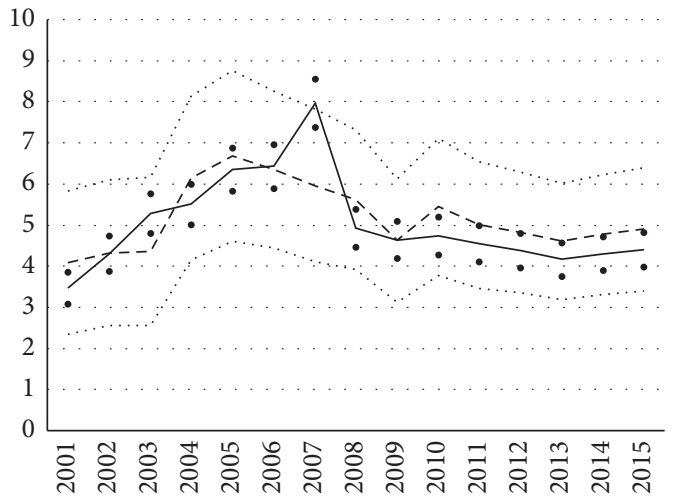

(b)

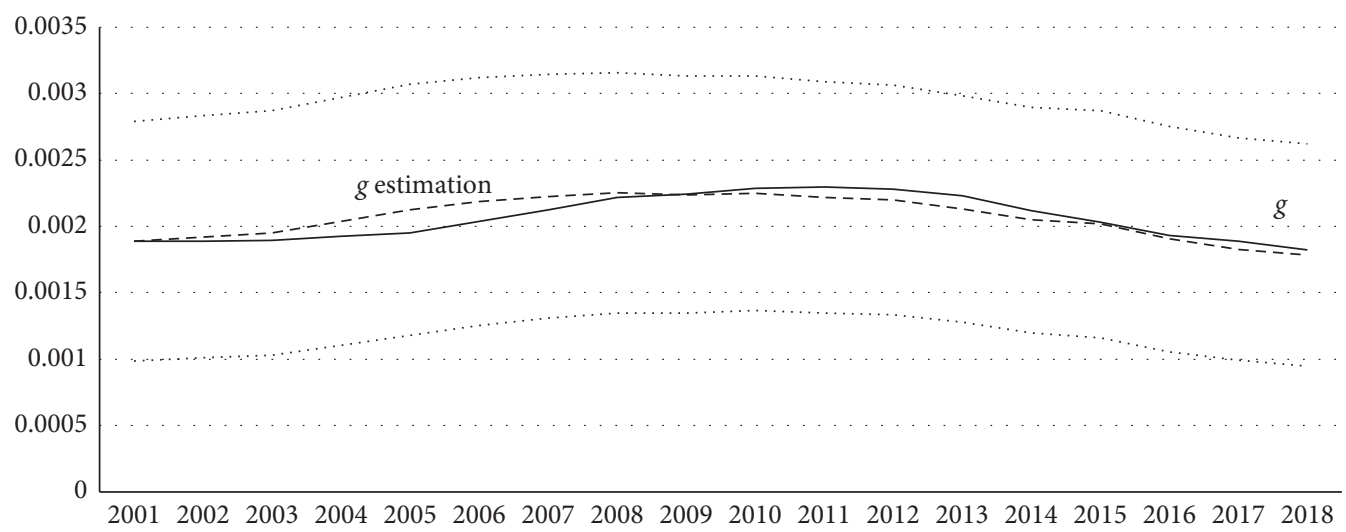

(c)

FIGURE 9: Dynamics of probabilities of transition to the drug user group for individuals from the risk groups in the age of (a) 18 years and (b) 25 years and (c) all age groups. On the vertical axis, $n$ is 10,000 .

the next year was a peak for the older generation. At the same time, the average probability of drug use initiation for all ages has no peaks on the graph during these years.

This phenomenon is explained by the fact that, before the adoption of the state antidrug program [21], the probability of drug use initiation continued to increase.
However, the main measures of the program were aimed at the younger population. Thus, the program had almost no impact on the process of drug addiction among adults older than 30 years.

Based on Figure 8, we can thus conclude that our model accurately describes the process of drug addiction development, 
and at the same time, the regression deviations from the point estimates of probability are in the $95 \%$ confidence interval for the point estimate (5), which demonstrates the adequacy of using only the first two principal components of the indicators $I_{1}, \ldots, I_{20}$.

\section{Forecasting}

Above, we have shown how our calculations can reproduce the data, thus validating the model. Most importantly, however, the results obtained also allow for a forecasting to illustrate the possibility of using the model for an advanced drug situation analysis in a region, leading to possible policy recommendations. Based on these results, we can draw conclusions about the structure and the number of drug addicts in the region.

We formed two scripts for this. The first scenario includes an optimistic forecast of indicators $I_{10}, \ldots, I_{12}$. The second is a pessimistic forecast of indicators $I_{10}, \ldots, I_{12}$ with equal averages of other indicators.

During the comparison of optimistic and pessimistic forecasts on the basis of the proposed model, it can be seen that the dynamics of drug addicts at older ages coincide, which is explained by the fact that it is extremely rare to see newly registered drug addicts over the age of 30 . However, the greatest change in the factors of the emotional and psychological state of the territory is observed at ages between 15 and 20. Thus, based on the proposed model, it is shown that, with the implementation of the development scenarios of St. Petersburg, considering the best emotional and psychological state of the society, the probability of narcotization of the population can be significantly reduced to almost the lowest possible level. At the same time, if the negative scenario is implemented, the probability of drug addiction will increase almost linearly, which will lead to a significant proportion of young addicts.

It should be noted that the optimistic scenario does not include such factors as the emergence of new types of drugs and changes in the population's attitude towards drugs.

Particular attention can be paid to the forecast of the number of drug addicts of 18 and 19. The number of drug addicts in these ages will increase according to the forecast, despite the general decline in the population in these ages. This phenomenon can be explained by the appearance of a second "peak" in the number of drug addicts at a younger age, shown in Figure 2. Thus, a further increase of this "peak" in the base forecast is predicted. At the same time, in the framework of an optimistic forecast, it is assumed that the number of drug addicts of this age will remain at the same level. This can happen with the successful implementation of antidrug measures to prevent the emergence of new "fashionable" types of drugs.

For comparison, Figure 10(c) shows the use of this model to obtain a forecast using only data up to 2014. Measurements of the number of drug addicts after 2014 are given to compare the accuracy of the model. It can be seen that, in most cases, the result does not go beyond the measurement error. This gives us an additional confidence on the forecasting provided by the model.
Thus, the natural conclusion for the strategy of St. Petersburg, taking into account in particular the risk of drug addiction among the young female population, is a need to create a benchmark opinion about drugs and drug use as a negative phenomenon among individuals from the target group. However, the implementation of such a scenario requires a careful registering of societal attitudes to drug use, as noted before in [2].

We may stipulate that the implementation of a St. Petersburg policy taking into account the provision of the best emotional and psychological state of the society, in order to reduce the consumption and harm from drug addiction, requires, on the one hand, actions of social support of the population and, on the other hand, educational actions to adjust sustainable behavioral patterns among people in the risk groups.

The multifactor model we proposed for the narcotization forecasting in cities with a high population density and a high rate of communication in the society allows assessing the size and age-sex structure of different phenomenological groups of population narcotization in the short, medium, and long terms. The proposed model allows taking into account features of the antidrug policy, implemented in the given territory, as well as the attitudes to drugs in the society.

The proposed model was tested in the forecasting of drug addiction spreading in St. Petersburg and allowed to get conclusions that the most significant factors of population narcotization are the factors of acceptance of drugs in the society.

Thus, the formation of healthy thinking, excluding the consumption of drugs in any situation, is the most realistic scenario of population narcotization counteraction [22].

Finally, we notice that, during the drug situation's development, an increase of the popularity of new types of drugs and an increase in drug addiction in general are possible until 2020 after a relative decline.

\section{Discussion}

Drug addiction simulation at the microlevel involved the dynamics of society concerning the different phenomenological states of narcotization. At the same time, in the model, there is no account given of the social relations between individuals, which is plausible only under an assumption of an essentially random nature of these relationships. But as the researchers have repeatedly noted, the importance of the environment of the individual in his/her commitment to drug use [2] as a further component of the model should involve the description of drug addiction spreading at the microlevel for each individual based exactly on his/her social relations.

Internal factors of drug use are individual for each member of the society and are determined, first of all, by the social environment of the individual, the exchange of information with other members of the society, and the fashion of certain types of drugs in the social environment. It is known [2] that different types of drugs are characterized by different methods, causes, and circumstances of 


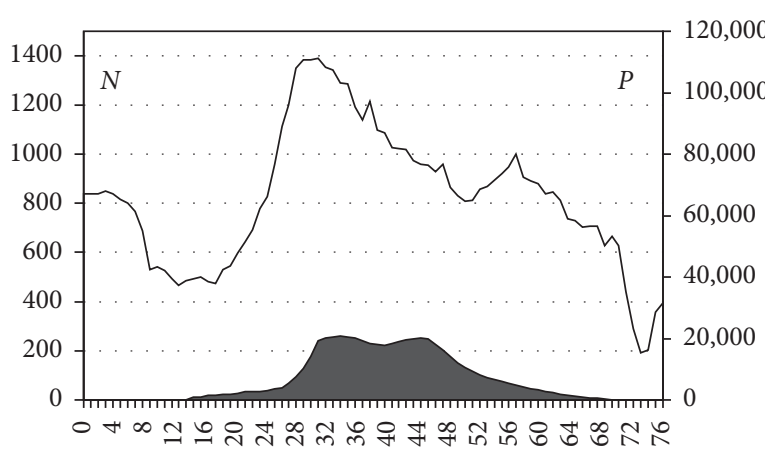

Drug users

Population at whole

(a)

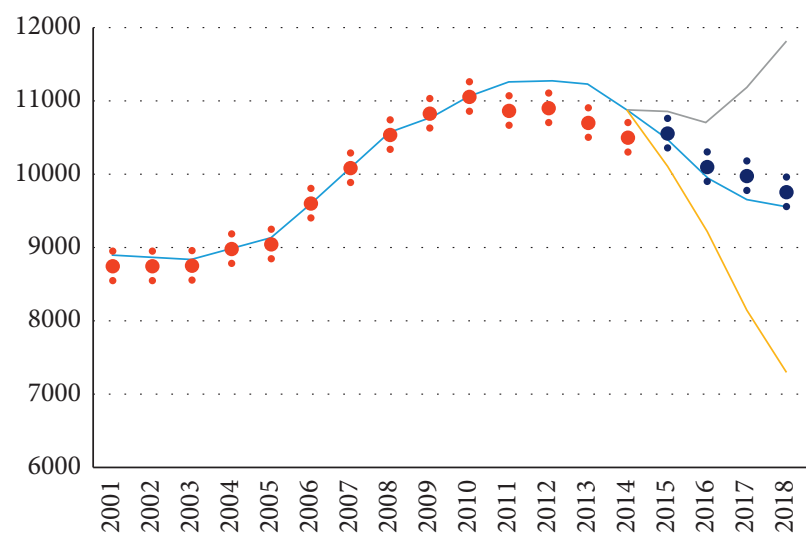

(c)

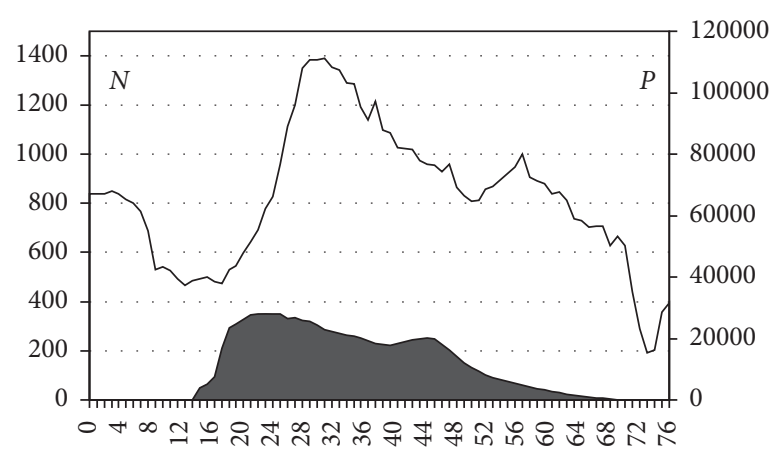

Drug users

Population at whole

(b)

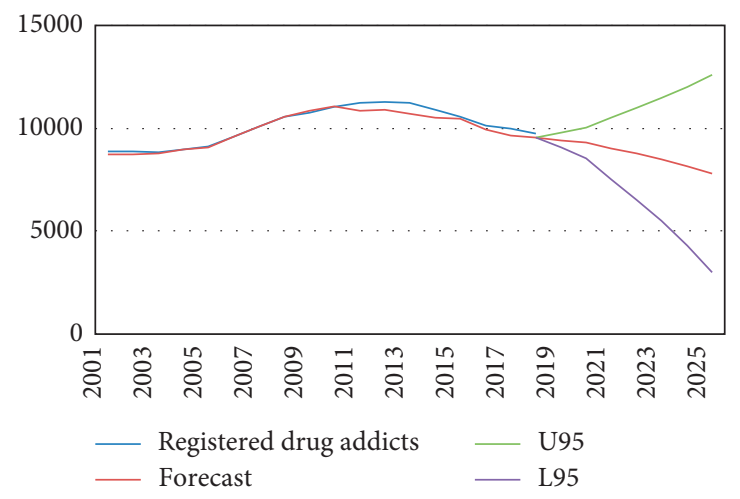

(d)

FIGURE 10: Drug addiction probability forecasting in St. Petersburg until 2020, taking into account the emotional and psychological state of the population, in the (a) optimistic scenario $I_{10}, \ldots, I_{12}$ and (b) pessimistic scenario $I_{10}, \ldots, I_{12}$. (c) Demonstration of the model forecast on historical data up to 2014. (d) Forecast of the number of drug addicts of all ages.

their reception, which determine getting of the individual to the appropriate group. Internal factors may be determined by the presence or absence of a connection with the distributors and consumers of drugs, for instance, since the transfer of drugs is made either by a direct contact or in a group.

The lack of data on the distribution of drugs from one individual to another individual forces us to consider a graph of social ties as being fully random, which is quite a rough first estimation. In order to assess the actual structure of this graph, it would be necessary to use special methods of establishing relationships between individuals, for example, an analysis of the social networks on the Internet. Social networks, being a kind of overt "society replica" accessible to direct observation, allow for an assessment of the prevalence of drug culture along a number of formal dimensions. Determination of the numerical characteristics of a social network segment would allow building a complex network model of population narcotization based on the data of this social network. The estimation of population narcotization based on a complex network model, obtained on the basis of such social network monitoring, may be delayed at this point due to the difficulty in obtaining a representative sample but would truthfully describe the psychological state of the society.
Thus, future population narcotization research, based on the data of social networks, will include two subtasks: (i) monitoring of social networks with the restoration of the graph topology of social ties and a classification of network nodes according to the criterion of their respective involvement in drug abuse and (ii) simulation of population narcotization. The authors consider investigation of the structure of social relations of drug users and its impact on the process of population narcotization as a priority direction of work in this area [23].

\section{Data Availability}

Data were curated by the authors and are available upon request.

\section{Conflicts of Interest}

The authors declare that they have no conflicts of interest.

\section{References}

[1] J. Ward, W. Hall, and R. P. Mattick, "Role of maintenance treatment in opioid dependence," The Lancet, vol. 353, no. 9148, pp. 221-226, 1999. 
[2] C. R. Bartol, Criminal Behavior: A Psychosocial Approach, Prentice Hall, Upper Saddle River, NJ, USA, 2004.

[3] B. V. Boev, "Modern mathematical modeling of the stages of development and spread of infectious diseases," Wiley, Hoboken, NJ, USA, 1991.

[4] B. V. Boev and V. M. Bondarenko, "The predictive model of drug addiction and HIV infection among young people," Microbiology, vol. 5, pp. 76-81, 2001.

[5] K. Keizer, S. Lindenberg, and L. Steg, "The spreading of disorder," Science, vol. 322, no. 5908, pp. 1681-1685, 2008.

[6] Y. N. Zakharov, "The methodology to evaluate the development of ict and e-government in St. Petersburg and the task of monitoring the implementation of activities of plan strategy of information society development," in Proceedings of the Internet and Modern Society: XIII All-Russian United Conference, Saint Petersburg, Russia, October 2010, http://conf. infosoc.ru/2010/thesis/PDF/192-194_Zakharov.pdf.

[7] United Nations Office on Drugs and Crime, World Drug Report 2015, United Nations Publication, New York, NY, USA, 2015.

[8] National Drug Control Strategy/the Whitehouse [website]URL: http://www.whitehouse.gov/sites/default/files/ondcp/ policy-and-research/ndcs_2014.pdf, (visited on 10/10/2014).

[9] R. J. MacCoun and P. Reuter, Drug War Heresies: Learning from Other Vices, Times, and Places, Cambridge University Press, Cambridge, UK, 2001.

[10] EMCDDA, Modelling Drug Use: Methods to Quantify and Understand Hidden processes-Luxembourg, Office for Official Publications of the European Communities, Brussels, Belgium, 2001, http://www.emcdda.europa.eu/attachements. cfm/att_80903_EN_Monograph6.pdf, EMCDDA Scientific Monograph Series, No 6.

[11] L. Wiessing, Pilot Project to Develop a Model of Geographical Spread of Drug Misuse in the European Union, European Monitoring Centre for Drugs and Drug Addiction, Lisbon, Portugal, 1999, http://www.emcdda.europa.eu/html.cfm/ index1374EN.html.

[12] V. A. Tsybatov, "Strategic planning of energy-efficient development of a region of the Russian federation," Economy of Region, vol. 14, no. 3, pp. 941-954, 2018.

[13] P. E. Meehl, Clinical versus Statistical Prediction: A Theoretical Analysis and a Review of the Evidence, University of Minnesota Department of Psychology, Minneapolis, MN, USA, 1954.

[14] S. Melike and K. Y. Degtiarev, Forecasting Enrollment Model Based on First-Order Fuzzy Time Series, World Academy of Science, Engineering and Technology, Paris, France, 2008.

[15] J. P. Caulkins, "Estimating elasticities of demand for cocaine and heroin with data from the drug use forecasting system," Final Report/United States Department of Justice, National Institute of Justice, Washington, DC, USA, 1995.

[16] Official site of federal drug control Service of Russia, http:// www.fskn.gov.ru.

[17] S. A. Mityagin, S. N. Bolbin, A. I. Drozhzhin, V. V. Ivanenkov, "An integrated approach to the evaluation of latency in the field of illicit drug trafficking, National Economy, Issues of Innovative Development," Master of Sciences, pp. 61-68, 2011.

[18] S. M. Inshakov, Latent Crime in the Russian Federation, p. 357, Ministry of Justice, Moscow, Russia, 2007.

[19] V. I. Starodubov, Tatarkin AI Impact of Addiction on the Socio-Economic Development of Society, Ural Branch of the Russian Academy of Sciences, Ekaterinburg, Russia, 2006.
[20] Monitoring of drug abuse and other psychoactive substances abuse in Orenburg: basic data and trends in the years 1994-2003, -ОренбурГ: ООО «Орен-знак», 2004, -84 с.

[21] Resolution of the Government of the Russian Federation of 13.09.2005 №561 «About the Federal Target Program Comprehensive Measures against Drug Abuse and Illegal Trafficking in 2005-2009».

[22] Anti-drug policy in St. Petersburg, http://anpolitic.spb.ru.

[23] S. A. Mityagin, "Assessing the impact of drug abuse on the energy security of the region," Magazine "Narkologiya», vol. 9, no. $117,2011$. 